\title{
Commonplace
}

\section{Things with Demmy Verbeke, head of KU Leuven Libraries Artes}

Demmy Verbeke

Published on: Jun 25, 2021

License: Creative Commons Attribution 4.0 International License (CC-BY 4.0). 
A question that I have lately been asking myself more and more is what the purpose is of academic libraries in the changing landscape of research and teaching. For example: the Open Access future is, to a growing extent, already here and librarians like myself need to ask themselves what role they want to play, if any, in this new world. So I welcomed the request to come up with 5 Things as an exercise in finding materials that might help to make up my mind.

\section{1/ The role of libraries in independent research}

Visit the web version of this article to view interactive content.

\section{Rede Karen Maex tijdens de Dies Natalis 2021}

In her Dies Natalis speech delivered on 8 January 2021, Karen Maex, the rector magnificus of the University of Amsterdam, stressed that libraries "not only connect and disseminate knowledge", but "also facilitate and generate it". They thus play a central role in maintaining the independence of academic research. However, this role is being eroded by commercial forces which control a large majority of scholarly communications. Her words are a strong reminder that the autonomy of universities is being threatened and that university libraries are a vital part of our defenses. 


\section{2/ Librarians as gatekeepers (computer says no)}

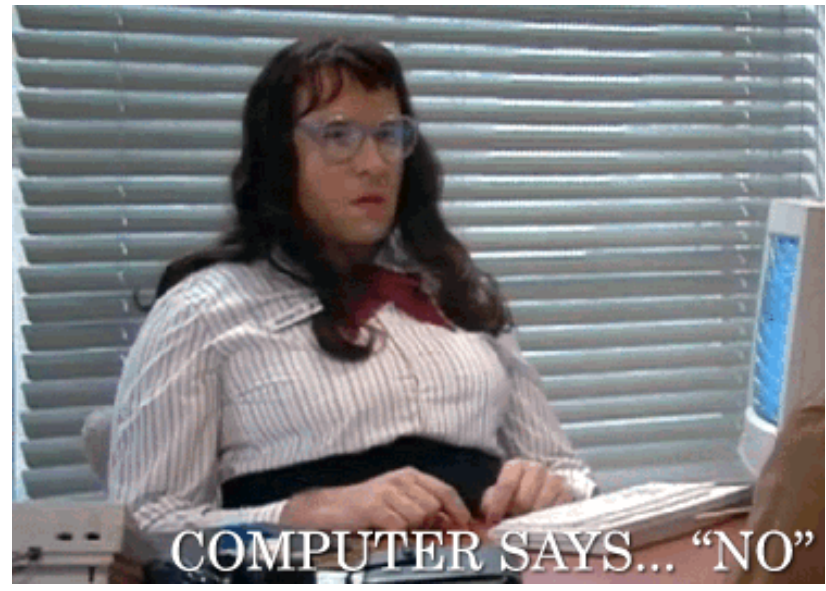

The essence of academic libraries has always been to make scholarly information accessible to as many people as possible. In the old days, librarians did this by building physical collections, which they would put on shelves in reading rooms or keep in storage. These collections were made available for free for the in-crowd of students and researchers of the same institution and typically made available for a very democratic fee to anyone else who might be interested. Librarians thus acted as friendly gatekeepers, as guardians and guides whose mission it was to share the collections that they, and the generations of librarians before them, had built carefully with all who is interested.

The digital turn gave the opportunity to optimize this mission by making the collections even more readily available to all with an internet connection. However, the walls surrounding academic libraries have grown higher instead of lower, not in the least by prohibitive licences to electronic collections designed to prevent access to all but the inner crowd. Librarians are supposed to protect this exclusivity and have thus become restrictive gatekeepers, pushed into a policing role which is contrary to their nature. 


\section{3/ Content vs Infrastructure}

\section{Visit the web version of this article to view interactive content.}

\section{Let's talk about...Open Science Infrastructure with Peter Suber}

In this recent interview, Peter Suber talks about the need for open infrastructure and calls for library support since this infrastructure will die or be bought up by for-profit players otherwise. Investing in infrastructure rather than content will require some changes, but are academic librarians not traditionally entrusted with budget to invest as wisely as possible in building and maintaining a system for scholarly communication? The choice between acting as money collectors for big commercial technology companies versus investing in an approach to scholarly communication which is more aligned with scholarly values then seems easily made.

\section{4/ Mission-driven vs profit-driven}

Visit the web version of this article to view interactive content.

One sentence to express something that took me years to figure out. And, to me, it beckons the question whether we want to spend our energy and budget on trying to slightly improve a broken system (knowing full well that our chance of succeeding is tiny) or rather on building an alternative that might or might not work.

\section{5/ Generous Thinking}




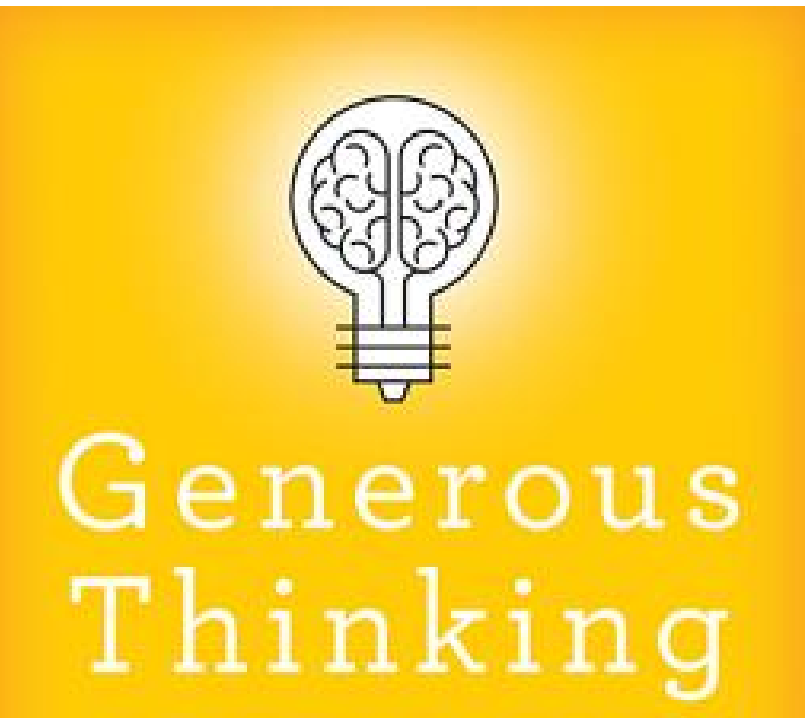

A RADICAL APPROACH

TO SAVING

THE UNIVERSITY

\section{KATHLEEN \\ FITZPATRICK}

Generous Thinking. A Radical Approach to Saving the University_(2019). by Kathleen Fitzpatrick. A book that I have wanted to reread as soon as I had finished it. There is so much in this book that I want to think about more, while I try to figure out how it affects my teaching, my research, and the decisions I make concerning the management of an academic library. It actually started with how I read this book, since, at first, I subconsciously started to dismiss everything that felt too "American" and marked by a different political and higher education context than the one I work in. After a while, I realised I was actually falling in the trap of being critical at the expense of engaging with the ideas. I started to see that the analysis is global: academics are not fundamentally ungenerous, but they work within structures and reward systems that favor competitiveness over community. But is that the central value of a university? What resonates particularly with me as a librarian is the argument that knowledge is not created to be hoarded and scholarship is written to be read. So we need to try to eliminate barriers in its production and dissemination, and certainly not introduce new ones. 


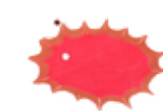

\section{-Demmy Verbeke}

>>> Subscribe to receive 5 Things to Think About from a different curator in your inbox each $\underline{\text { month }}<<<$ 